\title{
The Role of the Local Press in Shaping the Public Opinion about Political Issues
}

\author{
Dr. Nidal Ayoub Ali Abu Orabi Al Adwan \\ \& \\ Rakan Ayoub Ali (Abu Arabi Adwan) \\ $\mathrm{PhD}$ Student \\ University of Jordan
}

\begin{abstract}
The present study aimed to explore the role of the local press in shaping the public opinion about political issues in Jordan. A descriptive analytical approach was adopted. The researchers developed a questionnaire. The sample consists from 200 female and male students who were selected from the public universities located in the central province in Jordan. To be specific, they were selected from the (University of Jordan, the Hashemite University, and Applied Balqa University). It was found that the local press plays a very significant role in shaping the public opinion about political issues in Jordan. It was found that there isn't any statistically significant difference between the respondents' views which can be attributed to gender or university. The researchers recommend promoting awareness among university students about the role of the local press in addressing political issues and shaping the public opinion about political issues
\end{abstract}

Keywords: press, public opinion

\section{Introduction:}

Press is considered a very important and effective mean for promoting awareness about political issues. The local press plays a very significant role in promoting factual knowledge through displaying and analyzing information. It promotes such knowledge through displaying practical implications before the targeted category of people. It carries out such functions, especially when there is a political issue that the local public opinion is concerned in.

Promoting democracy in society requires providing freedom to media. That is required in order to hold public discussions about public issues. It's required in order to keep the public informed about the latest news. Based on the relevant literature, having press of high performance shall promote knowledge about political issues in society. It shall raise people's engagement in political events. It shall reduce the corruption levels in society (Nielsen et al, 2016).

Press has been always considered one of the four authorities in the state. It has been always considered a supervising authority and a mean for communication between citizens and decision makers. Freedom should be given to press in any society in order to promote democracy. Press should play a significant role in shaping the public opinion about issues, including political issues (Al-Enaimat, 2010).

The work of journalists in Jordan is regulated by the law of press and publication. Today, the Jordanian press enjoys much freedom. In fact, newspapers were issued by political parties. Press in Jordan enjoy adequate freedom in accordance with the provisions of the law. It plays a significant role in enforcing control over the performance of public institutions. It plays a significant role in detecting the mistakes committed by the public institutions (AlBatayneh, 2009). Press plays a significant role in shaping the public opinion. It plays a significant role in broadcasting news and information, and promoting knowledge and awareness among people. It plays a significant role in documenting events, and anniversaries. It is plays a significant role in promoting knowledge about known figures and sites and entertaining people.

Press plays a controversial role. It plays a significant role in shaping the public opinion. That is because press offers deep analysis and interpretations for economic and political issues, events, and decisions (Mahfoodh, 2017) There isn't any general nor specific theory that interprets the way the public opinion is shaped. However, the public opinion is considered one of the elements of the political life. It's one of the elements of the civilized society. It reflects the nature of the society. It is characterized with several characteristics. Such characteristics include: being dynamic, changing and instable. It should be noted that the measures taken for achieving political development can't be broadcasted without using media (Al-Enaimat, 2010).

There are various factors that affect the public opinion. Such factors include: internal and external factors. The external factors include: culture, cultural heritage, socialization, opinion leaders, incidents, parties, associations, media and rumors. Press is still considered ranked first in terms of its influence on the public opinion. 
Press is still ranked first in this regard because it seeks addressing political and social issues and analyzing them deeply. Therefore, it's capable of influencing and shaping the public opinion (Abed Al-Qader, 2015). Hence, it can be concluded that the local press plays a significant role in shaping the public opinion about political issues.

\section{Statement of the Problem}

During the contemporary age, there are various sources of information. Despite that, the local press -including the paper-based press- plays a significant role in achieving cultural and political development in the Jordanian society. However, due to having many political issues that the society is concerned in, the local press became an effective mean for shaping the public opinion about various political issues. However, to what degree is the local press capable in carrying out this function. Therefore, the problem of this study is represented in the following question: (How effective is the local press in shaping the local public opinion in Jordan about political issues?)

\section{The Study's Questions and Objective}

The present study aimed to explore how effective the local press is in shaping the local public opinion in Jordan about political issues. To meet the study's goal, the researchers aimed to answer these questions:

Q.1. How effective is the local press in shaping the local public opinion in Jordan about political issues from the perspective of the students enrolled in the public universities?

Q.2.Is there any statistically significant difference- at the statistical significance level of $(a=0.05)$ - between the respondents' attitudes in this regard which can be attributed to (gender or university)?

\section{The Study's Significance}

-The present study is significant because it sheds a light on the reality of the role of the local press in shaping the public opinion about political issues in Jordan. The local press isn't limited to the local newspapers. In fact, it involves other means that broadcast news, such as: television and radio. Today, it addresses many local and international issues due to globalism

- The present study is significant because press plays a significant role in promoting awareness among society members about political issues. Press is employed by the government and political bodies and associations for displaying several views on political issues

\section{Definition of Terms}

\section{The study's terms are defined below:}

Press: It refers to all the means of media. Such means include: daily, and weekly newspapers, and magazines, (Ma'ali, 2008: 6).

Political issues: They include the issues and problems related to politics and the regime in the state (Abed AlQader, 2015: 6)

Public opinion: It refers to the stand of the majority of people on a specific issue they are concerned in (AlEnaimat, 2010: 33).

\section{The Study's Limits}

The limits of the present study are presented below:

-Spatial limits: The present study targets public universities in Jordan

-Temporal limits: The present study was conducted during (January- March, 2020).

-Human limits: The researchers selected a sample consists from students who were enrolled at the public universities located in the central province in Jordan. To be specific, the selected universities are: (the University of Jordan, the Hashemite University, and Applied Balqa University).

\section{Previous Studies}

\section{The researchers reviewed several studies:}

Mahfoodh (2017) aimed to explore the role of the Omani Press in shaping the public opinion about the government procedures related to the oil prices. He adopted an analytical descriptive approach. He used the questionnaire tool which consists from (47) items. The sample consists from 400 male and female individuals. It was found that the Oman newspaper is ranked first in terms of the number of readers.

Al-Watan newspaper is ranked second and Al-Vision newspaper is ranked third. Al-Shabiba newspaper is ranked fourth. It was found that readers are motived to read Omani newspapers in order to acquire knowledge about the local events and issues and expand their knowledge.

El Issawi \& Cammaerts (2016) aimed to explore the role of Egyptian journalists in shaping the public opinion in Egypt. Through conducting interviews and reviewing the relevant literature, it was concluded that the Egyptian 
journalists play a significant role in monitoring public bodies after the reign of Mubarak. During the latter period, the Egyptian press was employed for the favor of ones adopting radicalism.

Abed Al-Qader (2015) aimed to explore the extent of knowledge possessed by young people about the political terms used in the political articles of daily newspapers. A survey was used and a descriptive approach was adopted. The sample consists from 300. Young individuals who live in Amman. Those individuals were selected from universities and press institutions. It was fond that many respondents (sometimes) read the daily newspapers (i.e. three days a week or more). Most of the respondents read paper-based newspapers. Most of the respondents read the political news articles. Most of the respondents suggest that the name of the author of the news article attract them to read it. It was found that news article enable young people to understand the local political changes and events. It was found that news article enable young people to change their political views and concepts. It was found that news article enable young people to expand their knowledge about political terms.

Shtayat (2012) shed a light on the significant role of media in shaping the political attitudes of the students enrolled in Jordanian universities. A descriptive approach was adopted. The sample consists from 380 male and female students. Those students were selected from the Middle East University and Yarmouk University. It was found that the respondents are satisfied with the way the Jordanian newspapers address the political issues. It was found that the respondents believe that there is little freedom given to the Jordanian newspapers when writing political news articles.

Al-Enaimat (2010) aimed to explore the role of the Jordanian daily press in achieving political development. He adopted a descriptive analytical approach. He used the content analysis method. The sample consists from 48 articles published in Jordanian newspaper (i.e. Al-Rai, and Al-Arab Al-Yaom). It was found that the Jordanian press doesn't provide adequate attention to political development. For instance, $8.8 \%$ of the articles shed a light on political development. It was found that the Jordanian daily newspaper don't publish articles about political development in a daily manner. That applies unless there are events related to political development. Such events include: the parliament elections and etc..

Azzam and Katebi (2010) aimed to explore the attitudes of Jordanians towards the role of the Jordanian media in addressing several security, political, social and economic issues. They aimed to explore the relationship between these attitudes and demographic characteristics. The analytical descriptive approach is adopted. It was found that the extent of the respondents' satisfaction with the performance of the Jordanian media is negative. It was found that the performance of the Jordanian media in enforcing control over the measures taken by the parliament and the public institutions is poor. It was found that the government enforces strict control over the Jordanian media. It was found that the extent of credibility of Jordanian media is moderate.

Bu Thekra (2009) aimed to shed a light on the terms and expressions used by electronic press. The sample consists from several articles published in electronic daily newspapers in Algeria. The descriptive analytical approach was adopted. The content analysis method was used. Several results were reached. For instance, it was found that some journalists are criticized for using slang and borrowed words. It was found that the journalists use words that are derived from other words.

\section{Comments on the aforementioned studies}

The aforementioned studies shed a light on the role of press- especially paper-based press- in shaping the public opinion about political issues. The present study identifies the major role of press in promoting political awareness among the members of the society. Based on the aforementioned studies, electronic newspapers and websites are read more than paper-based newspapers. The aforementioned studies differ from each other in terms of the population. The present study differs from the aforementioned studies in terms of the subject. For instance, the present study aimed to explore how effective the local press is in shaping the local public opinion in Jordan about political issues

\section{The Study's Approach}

The researchers adopted the descriptive analytical approach.

\section{The Study's Population}

The study's population consists from all the students enrolled in public universities in Jordan.

\section{The Study's Sample}

The study's sample was selected through using the stratified random sampling method. The sample consists from 200 students who were selected from the public universities located in the central province in Jordan. To be specific, they were selected from the (University of Jordan, the Hashemite University, and Applied Balqa University). Information about the sample is listed in table (1) below 
Table (1): Distribution of the sample in accordance with gender and university

\begin{tabular}{|c|c|c|c|}
\hline Variable & Category & Frequency & Percentage $\%$ \\
\hline \multirow[t]{3}{*}{ Gender } & Male & 104 & 52.0 \\
\hline & Female & 96 & 48.0 \\
\hline & Total & 200 & $\% 100$ \\
\hline \multirow[t]{4}{*}{ University } & $\begin{array}{l}\text { The University of } \\
\text { Jordan }\end{array}$ & 71 & 35.5 \\
\hline & $\begin{array}{l}\text { The Hashemite } \\
\text { University }\end{array}$ & 66 & 33.0 \\
\hline & $\begin{array}{ll}\text { Applied } & \text { Balqa } \\
\text { university } & \end{array}$ & 63 & 31.5 \\
\hline & Total & 200 & $\% 100$ \\
\hline
\end{tabular}

\section{The Study's Instrument}

The present study aimed to explore how effective the local press is in shaping the local public opinion in Jordan about political issues. It aimed to explore that from the perspective of the students enrolled in public universities in Jordan. The researchers developed a questionnaire that consists from two parts. The first part collects data about the characteristics of the sample. Such characteristics include: gender and university. The second part collects data about how effective the local press is in shaping the local public opinion in Jordan about political issues. It consists from seven items. The five point Likert scale was adopted. This scale consists from 5 rating categories. These categories include: to a very great extent, to a great extent, to a moderate extent, to a small extent, to a very small extent. They represent the following scores respectively: 5, 4, 3, 2 and 1.

\section{Validity of the Instrument}

The researchers measured the validity of the questionnaire through passing the questionnaire to a panel of experts in order to assess it based on their expertise.

Reliability of the Instrument

The researchers measured the reliability of the questionnaire through calculating Cronbach alpha coefficient value. The latter value is 0.912 which is an accepted value.

\section{The Study's Variables}

\section{The study's variables include:}

-The independent variable: It's represented in the degree to which the local press shapes the public opinion about political issues in Jordan from the perspective of the students enrolled in the Jordanian public universities.

-The dependent variable: It's represented in the respondents' attitudes towards the degree to which the local press shapes the public opinion about political issues in Jordan. Such attitudes are measured through the items of the questionnaire.

\section{The method of statistical analysis:}

To meet the study's goal, the SPSS program was used to analyze data and reach results. The following statistical methods were used:

- Cronbach alpha coefficient value was calculated to measure the reliability.

-Frequencies and percentages were calculated to explore the attitudes of the respondents

-Multivariate analysis of variance was conducted.

The following criteria were adopted by the researchers for classifying means:

2.34 or more: high

1.67-less than 2.34: moderate:

Less than 1.67: low

\section{The Study's Results:}

The study's results are presented below:

Results related to the study's first question:

Q.1. How effective is the local press in shaping the local public opinion in Jordan about political issues from the perspective of the students enrolled in the public universities?

To answer this question, means and standard deviations were calculated. Table (2) below presents these values 
Table (2): How effective the local press is in shaping the local public opinion in Jordan about political issues from the perspective of the students enrolled in the public universities

\begin{tabular}{|l|l|l|l|l|}
\hline No & Statements & S.D & M & Level \\
\hline 4 & $\begin{array}{l}\text { I believe that the local press seeks promoting } \\
\text { specific political views among citizens }\end{array}$ & .743 & 4.27 & High \\
\hline 5 & $\begin{array}{l}\text { For acquiring information about the political } \\
\text { events, I rely on the local press }\end{array}$ & 1.093 & 3.90 & High \\
\hline 3 & $\begin{array}{l}\text { The local press provides readers with adequate } \\
\text { information about political issues }\end{array}$ & 1.272 & 3.70 & High \\
\hline 6 & $\begin{array}{l}\text { I seek acquiring information in a regular manner } \\
\text { from the local press }\end{array}$ & 1.244 & 3.60 & High \\
\hline 7 & $\begin{array}{l}\text { The local press is provided with adequate } \\
\text { freedom }\end{array}$ & 1.073 & 3.55 & High \\
\hline 2 & $\begin{array}{l}\text { Political parties rely on the local press to } \\
\text { promote their ideas }\end{array}$ & 1.162 & 3.17 & High \\
\hline 1 & $\begin{array}{l}\text { I believe that the local press seeks shaping the } \\
\text { public opinion }\end{array}$ & 1.226 & 3.05 & High \\
\hline & Total & .686 & 3.60 & High \\
\hline
\end{tabular}

Table (2) presents how effective the local press is in shaping the local public opinion in Jordan about political issues from the perspective of the students enrolled in the public universities. The total mean is 3.60 which is high. The standard deviation is 0.686 .

The mean of statement (4) is 4.27 which is high. The standard deviation of the latter statement is 0.743 . The latter statement states the following: (I believe that the local press seeks promoting specific political views among citizens).

The mean of statement (1) is 3.05 which is high. The standard deviation of the latter statement is 1.226 . The latter statement states the following: (I believe that the local press seeks shaping the public opinion).

It was found that the local press plays a significant role in shaping the local public opinion in Jordan about political issues. The latter result is attributed to the attention provided by the students in public universities to the local press to get news about the local political issues. The local press publishes reports and analysis for news and conduct investigation about various political issues. Thus, it plays a significant in shaping the local public opinion about the political issues.

The results of this study are consistent with the results concluded by Abed Al-Qader (2015). The latter researcher suggests that reading the articles of the local newspapers assists people in understanding the local political events, and changes. He adds that reading the articles of the local newspapers may change people's political views. Shtayat (2012) suggests that reading the articles of local newspapers shall promote knowledge about local issues

\section{Results related to the second question}

Q.2.Is there any statistically significant difference- at the statistical significance level of $(a=0.05)$ - between the respondents' attitudes in this regard which can be attributed to (gender or university)?

To answer this question, means and standard deviations were calculated. Table (3) below presents these values

Table (3): The respondents' attitudes in accordance with (gender or university)

\begin{tabular}{|l|l|l|l|l|}
\hline Variables & Category & No & S.D & M \\
\hline \multirow{2}{*}{ Gender } & Male & 104 & .691 & 3.60 \\
\cline { 2 - 5 } & Female & 96 & .684 & 3.61 \\
\hline \multirow{3}{*}{ University } & Jordanian & 71 & .685 & 3.60 \\
\cline { 2 - 5 } & Hashemite & 66 & .725 & 3.58 \\
\cline { 2 - 5 } & Balqa Applied & 63 & .655 & 3.63 \\
\hline
\end{tabular}

Based on table (3), it appears that there are differences between the respondents' attitude in this regard which can be attributed to gender and university. To explore whether these differences are statistically significant or not at the statistical significance level of $(a=0.05)$, multivariate analysis of variance was conducted. The results of the latter analysis are presented below in table (4): 
Table (4): The results of the multivariate analysis of variance

\begin{tabular}{|l|l|l|l|l|l|}
\hline Source & Sum of Squares & df & Mean Square & F & Sig. \\
\hline Gender & .011 & 1 & .011 & .023 & .879 \\
\hline University & .065 & 2 & .032 & .068 & .935 \\
\hline Error & .000 & 0 &. &. &. \\
\hline Total & 93.758 & 196 & .478 & & \\
\hline
\end{tabular}

The statistical significance level is $(\mathrm{a}=0.05)$

Based on table (4), it was found that there isn't any statistically significant difference- at the statistical significance level of $(\mathrm{a}=0.05)$ - between the respondents' attitudes in this regard which can be attributed to (gender or university). The significance values for gender and university are 0.879 and 0.935 respectively. The latter values are not statistically significant.

The latter result is attributed to the fact that all the male and female members of the society have been providing attention to political issues. Such attention can be manifested through the engagement of males and females in political talk shows. The latter result is attributed to the fact that the members of the Jordanian society share similar views regardless of the university they are enrolled at.

\section{Recommendations:}

In the light of the study's results, the researchers recommend the following:

-Promoting awareness among the university students about the significant role of the local press in broadcasting news about political issues. The researchers recommend promoting awareness among the university students about the significant role of the local press in shaping the public opinion about political issues.

-Encouraging university students to engage in the events organized by the local press for holding discussions about political and international politics

\section{References:}

Ma'ali, Khalid Ameen (2008). The impact of electronic press on the achievement of political development in Palestine (the West Bank and Gaza) during 1996-2007. MA thesis. Al-Najah University. Palestine.

El Issawi, Fatima and Cammaerts, Bart (2016) Shifting journalistic roles in democratic transitions: lessons from Egypt. Journalism, 17 (5). pp. 549-566. ISSN 1464-8849 DOI: 10.1177/1464884915576732

Nielsen, R., Cornia, A., Kalogeropoulos, A. (2016) Challenges and opportunities for news media and journalism in an increasingly digital, mobile, and social media environment. Council of Europe report DGI(2016)18.

Shtayat, Izdehar (2012) The Impact of The Press Opinion on The Formation of The Political Attitudes of The Jordanian University Youth at The Universities of The Middle East and Yarmouk University. Master thesis Universities of The Middle East, Jordan.

Mahfoodh, Deena Ramiss (2017) The Role of the Omani Press in Shaping Public Opinion about the Government's Measures to Cope with the Drop in Oil Prices. Master thesis Universities of The Middle East, Jordan.

Al-Enaimat, Mohammad (2010). The role of the Jordanian press in achieving political development: An analytical study for the news article published in Al-Rai and Al-Arab Al-Yaom during 2008-2009. MA thesis. The Middle East University. Jordan

Al- Batayneh, Rafe' Shafeeq (2009). Political reform in Jordan: A vision for the political development. $1^{\text {st }}$ edition. Amwaj publication and distribution house. Amman

Abed Al-Qader, Tareq Mohammad (2015). The extent of knowledge possessed by the readers of daily newspaper about the political terms used in the political news articles: A study surveying young people whose age is within the range of 20-40 year. MA thesis. Petra University. Jordan

Azzam, Abed Al-Majeed, and Katebi, Hadya (2010). The attitudes of Jordanians towards the performance of the Jordanian media: An exploratory study. The Journal of Damascus University. 26(3+4). 